\title{
LA RESISTENCIA DEL PUEBLO HARAKBUT. EL CASO DE LA FEDERACIÓN NATIVA DEL RÍO MADRE DE DIOS Y AFLUENTES (FENAMAD) VERSUS HUNT OIL COMPANY, REPSOL EXPLORACION Y PLUSPETROL CORPORATION ${ }^{(1)}$
}

\author{
HARAKBUT LLAQTAPA HAPIPAKUYNIN. FEDERACION NATIVA \\ DEL RIO MADRE DE DIOS Y AFLUENTES NISQAMANTA (FENAMAD) \\ TUPASQANKUMANTA HUNT OIL COMPANY, REPSOL EXPLORACION \\ HINALLATAQ PLUSPETROL CORPORATION NISQA IMA
}

\begin{abstract}
THE RESISTANCE OF THE HARAKBUT PEOPLE. THE CASE OF THE NATIVE FEDERATION OF THE RIVER MADRE DE DIOS AND TRIBUTARIES (FENAMAD) VERSUS HUNT OIL COMPANY, REPSOL EXPLORATION AND PLUSPETROL CORPORATION
\end{abstract}

Markoni Gonzales Pichihua(2)

\begin{abstract}
Ch'uyanchakuy: Kay llankaywan rimasaq, ñawpata, regimen politico nisqata, economico, kawsaykunamantawan Harakbut llaqtamanta, chaymanta rimasaq imanyanatas paqarira chay Proceso Constitucional de Amparo Federacion Nativa del Rio Madre de Dios y Afluentes nisqamanta (FENAMAD), Hunt Oil Company, Repsol Exploración y Pluspetrol Corporationtawan churasqanman. Kaypi qelqashani imaynatas tupanku juridico chaqkuypi ñawpa yunk llaqtakuna Peru suyumanta Harakbut, Yine Matsigenkatawan, FENAMAD sayaparikusqanwan, chay empresas petroleras nisqakunawn.
\end{abstract}

Yuyaysapa simikuna: Runakunamanta kamachina hathun qelqa, Qhawasqa yachay, Harakbut, Yine, Matsigenka Ayllukuna, FENAMAD

(1) Esta investigación fue desarrollada en el Laboratorio de Investigación en Derecho, Sociedad y Política (LIDSP), de la Facultad de Derecho y Ciencias Sociales de la Universidad Nacional de San Antonio Abad del Cusco. Fue posible gracias a la valiosa cooperación de Magdalena Ruiz, de la Reserva Ecológica Chontachaca, y de Marianne van Vlaardingen, de Pantiacolla Lodge Manu National Park.

(2) Abogado por la Universidad Nacional de San Antonio Abad del Cusco. Socio fundador del Laboratorio de Investigación en Derecho, Sociedad y Política (LIDSP), de la Facultad de Derecho y Ciencias Sociales de la Universidad Nacional de San Antonio Abad del Cusco. Socio fundador del Instituto Intercultural de Estudios Sociales y Políticos (IDESPO). 
Resumen: El objetivo del presente trabajo es describir, históricamente, el régimen político, económico, cultural y social del pueblo Harakbut, y explicar el origen y desarrollo del Proceso Constitucional de Amparo iniciado por la Federación Nativa del Río Madre de Dios y Afluentes (FENAMAD) contra Hunt Oil Company, Repsol Exploración y Pluspetrol Corporation. Detalla el conflicto fáctico y jurídico de los pueblos indígenas de la Amazonía peruana Harakbut, Yine y Matsigenka, representados por FENAMAD, con las empresas petroleras transcontinentales.

Palabras claves: Derecho Indígena. Teoría Crítica. Capitalismo. Pueblos Harakbut, Yine y Matsigenka. FENAMAD.

Abstract: The objective of this paper is to describe, historically, the political, economic, social and cultural regime of the people. Harakbut, and explain the origin and development of the constitutional process of Amparo initiated by the Native Federation of the Madre de Dios River and Tributaries (FENAMAD). Hunt Oil Company, Repsol Exploration and Pluspetrol Corporation. It details the factual and legal conflict of the Amazon Peruvian indigenous peoples Harakbut, Yine and Matsigenka, represented by FENAMAD, against the transcontinental oil companies.

Key words: Indigenous Law. Critical Theory. Capitalism. Harakbut, Yine and 
Matsigenka Indigenous Peoples. FENAMAD.

\section{El régimen de producción de las comunidades nativas en la selva peruana.}

La selva peruana (también llamada región amazónica) abarca más del 57\% de todo el territorio nacional, en los departamentos de Loreto, Ucayali, Amazonas, San Martín, Madre de Dios y parcialmente en los departamentos de Puno, Cusco, Junín, Pasco y Huánuco. Geográficamente este territorio es el más diverso por su flora y fauna, culturalmente, también es el más diverso por la existencia de muchas y variadas etnias, su riqueza lingüística y etnohistórica.

El ser humano migró hacia la selva peruana hace unos quince mil años, proveniente del norte del continente americano. Llegó con varias habilidades humanas desarrolladas, adquiridas a lo largo de miles de años, con técnicas de caza y de recolección básicas, lenguaje esencial, relaciones sociales centradas en tareas básicas de supervivencia, instrumentos de trabajo rústicos, etc. ${ }^{(3)}$, y en este territorio nuevo desarrollaron aún más esas habilidades y adquirieron otras.

Antes de la invasión española, periodo precolombino (15000 a.c. aprox. - 1532 d.c.), el régimen económico-social de los grupos sociales existentes en la región amazónica consistía en, por una parte, la caza de animales, la recolección de frutos y tubérculos y la pesca precaria, utilizando instrumentos de trabajo rudimentarios como palos, piedras talladas, etc., utilizando ciertas técnicas trasmisibles a las futuras generaciones ${ }^{(4)}$. La caza de animales se efectuaba en grupo mediante la cooperación simple, sobre todo cuando se trataba de grandes animales, y lo realizaban solo varones, mientras que la recolección estaba reservada para las mujeres y niños. La dieta de estos primeros hombres estaba vinculada directamente a lo que les proporcionaba la naturaleza, cuando se agotaban, migraban para encontrar su

(3) "Hubo un momento en la historia de todos los pueblos, en que las actividades de subsistencia se restringían a la apropiación y consumo de los recursos de vida - animales, plantas, o minerales -, tal cual ellos estaban en la naturaleza. Debido a las limitadas capacidades heredadas naturalmente por nuestra especie, solo había que disponer de instrumentos que facilitaran tal apropiación. Los instrumentos permitían ampliar esas capacidades y adquirir otras que no se tenían: por ejemplo, recursos para cortar o hendir materias duras; mientras que la carencia de colmillos poderosos o garras, podía ser suplida por piedras, maderas o huesos duros, con puntas o filos". Extraído de: Lumbreras, Luis Guillermo, Kaulicke, Peter y otros, "Compendio de Historia Económica del Perú", Tomo I: Economía Prehispánica..., pág.: 25.

(4) "El ser humano se diferencia de las demás especies de animales por su capacidad de convertir la habilidad de crear instrumentos en un recurso susceptible de ser transmitido socialmente, de unos individuos a otros, a lo largo de generaciones. Debido a esta habilidad, las técnicas - que son los procesos de creación y uso de los instrumentos - son heredables, como lo son los recursos biológicos, genéticamente transmisibles en todas las especies vivas. Las técnicas, es decir, las maneras de hacer y usar los instrumentos, se almacenan en la memoria colectiva mediante códigos sociales similares a los códigos genéticos. Aquellos códigos son transmitidos socialmente a cada uno de los individuos que participan del grupo social donde tales códigos están almacenados". Ibídem. 
alimento. Después, mediando todo un proceso histórico de domesticación de ciertos tubérculos, se desarrolla la agricultura ${ }^{(5)}$ y en algunos lugares, la crianza de animales menores.

De otra parte, estos seres humanos, principalmente cazadores y recolectores, vivían en pequeños grupos, denominados hordas o bandas, eran básicamente nómadas, había una división social del trabajo simple o también llamada natural. Los miembros de estas hordas o bandas estaban relacionados por lazos de parentesco, vínculos de sangre, y lo integraban uno o varios varones, un conjunto de mujeres y los hijos de ellos. En el transcurso del tiempo, el número de integrantes de la horda aumentaba y algunos miembros salían de él, por temas de suministros alimenticios, territorio, etc. ${ }^{(6)}$. Por otro lado, surgía la necesidad de hacer alianzas o uniones con otras hordas o bandas, por motivos de sobrevivencia, para hacerle frente al ambiente hostil y sobre todo para dominar la naturaleza y extender sus territorios, surge así la organización gentilicia de la sociedad ${ }^{(7)}$. Finalmente, varias organizaciones gentilicias conformaban una tribu. La tribu fue una forma de organización social desarrollada, que prevalecía en la época de la invasión española en 1532, y que existe aún en varias regiones selváticas del país.

En la época de expansión del Tahuantinsuyo, los Inkas no concretaron la conquista e incorporación total de la región amazónica a los dominios Inkas, por diversos motivos, territorio agreste, resistencia étnica, etc., sin embargo, y con más frecuencia, realizaban intercambios de ciertos productos alimenticios y determinados instrumentos. A los pueblos indígenas ubicados en las cuencas de los ríos Urubamba y Apurímac, los Inkas los denominaban, de manera genérica,

(5) "La yuca o mandioca, el camote (boniato o batata), la arracacha y otros tubérculos y rizomas son plantas, cuya domesticidad debe asociarse a un proceso de ese tipo (se refiere al proceso denominado conuco o millpa, mediante el cual se limpia el área donde se pretende cultivar, por lo general quemando y talando árboles). En la cuenca baja de la Amazonía, se han encontrado poblaciones muy antiguas, cerca del octavo milenio, que ya eran, al parecer, cultivadoras". Ídem, pág.: 77, lo entre paréntesis y cursiva es nuestro.

(6) "Las bandas no son estáticas, a menos que se establezcan límites para la procreación. Crecen, aumentan en número de miembros, de año en año. Las bandas muy numerosas no son prácticas, ni para las tareas de caza ni para la distribución de las presas para el consumo, porque pueden fácilmente agotar los recursos naturales accesibles. Por ello, deben ser numéricamente moderadas. Frente al incremento de los miembros, la solución es dividirse, y eso es así también entre los primates". Ídem, pág.: 27. (7) "El paso a la organización gentilicia exigía un cambio radical en las relaciones entre los sexos. Dentro de la horda, prevalecían las relaciones sociales más desordenadas entre hombre y mujer; era corriente el incesto, y ello entorpecía el desarrollo del hombre primitivo. Era una necesidad vital e imperiosa el que las relaciones entre los sexos se ordenasen, estableciendo la exogamia (prohibición de relaciones conyugales entre consanguíneos). Se vio que los grupos primitivos en que no se toleraba el incesto se desarrollaban más rápidamente que aquellos en que las relaciones matrimoniales entre consanguíneos eran habituales. Se comenzó a difundir la práctica de casarse individuos pertenecientes a "gentes" distintas, con lo que venían a ampliarse las posibilidades de la cooperación simple y se impulsaba el desarrollo de las fuerzas productivas". Extraído de: K. Ostrovitiánov, L. Leóntiev y otros, "Manual de Economía Política"..., pág.: 24. 
"Antis", y formaban parte, según los Inkas, de la región del Antisuyo, una de las cuatro regiones o divisiones políticas, económicas, geográficas y administrativas del Tahuantinsuyo, posteriormente, en las épocas colonial y republicana, y debido a la difusión de las crónicas de Garcilaso, se comenzó a emplear el término "Chunchu" o "Chuncho" para referirse a los pueblos originarios amazónicos.

Durante el periodo colonial $\left(1532-1824^{(8)}\right)$, los pueblos de la región amazónica sufrieron varios cambios radicales coercitivos en sus territorios, su régimen económico, su cultura, su cosmovisión, su organización social, sus costumbres, en resumen, en su vida en sociedad. Los invasores provenientes de España introdujeron fundamentalmente dos formas de organización social, el régimen del vasallaje o feudal primero, a imagen y semejanza del europeo, y después el régimen capitalista incipiente, aunque también en algunos lugares puso en práctica el régimen esclavista. Junto con estos cambios, los invasores introdujeron nuevos cultivos, animales e instrumentos de trabajo, así como también, impusieron, a sangre y fuego, su cultura, sus instituciones políticas, sus normas jurídicas, sus conceptos de propiedad, territorio y posesión, su religión, su idioma, sus costumbres y su ideología ${ }^{(\mathbf{9})}$.

Los invasores una vez instalados en territorio peruano, se apresuraron de reproducir el régimen económico preponderante en España en aquellos años, el régimen feudal o vasallaje, insertándolo en los rubros de la agricultura, la maderera y la minería fundamentalmente, utilizando para ello los conocidos "requerimientos a los indios"(10), implantaron la "encomienda" y las "mercedes"(11). Por otro lado, los invasores tenían necesidad de legitimar lo que ellos llamaban su propiedad, entonces recurrieron a las máximas autoridades de España, los Reyes y el Papa, este último tenía la facultad de emitir bulas refrendando el derecho de apropiación,

(8) Aunque formalmente la declaración de la independencia fue el 28 de julio de 1821, fueron con las batallas de Junín ( 6 de agosto de 1824) y de Ayacucho (9 de diciembre de 1824) que se sellaron definitivamente la independencia del Perú, al menos en términos formales.

(9) "los españoles no solamente introdujeron nuevos cultivos, animales y tecnología, sino que también trasladaron nuevas instituciones y organizaciones económicas, como la moneda, el trabajo asalariado, las ciudades y la hacienda o latifundio agropecuario. Dieron inicio a un nuevo sector productivo, destinado a cumplir un rol protagónico entre nosotros, como la minería, y vincularon a la economía peruana con el resto del mundo, precisamente de la mano de este nuevo sector". Extraído de: Noejovich, Hector, Salazar-Soler, Carmen y otros, "Compendio de Historia Económica del Perú", Tomo II: Economía del Periodo Colonial Temprano, Editor: Carlos Contreras, primera edición, Edit.: Banco Central de Reserva del Perú y el Instituto de Estudios Peruanos, Lima, 2009, pág.: 13.

(10) "La figura institucional que se implementó fue el "requerimiento". El caudillo español, a través del notario, requería la conversión a la fe católica: si los indios acataban y, como buenos cristianos se sometían a la autoridad del rey, se convertían en vasallos de la Corona; caso contrario, había una "justa causa" para hacerles la guerra y esclavizarlos". Ídem, pág.: 40.

(11) "La solución al problema de la necesidad de mano de obra para Nueva Castilla, como se denominó inicialmente al futuro virreinato del Perú, fue el desarrollo de la "encomienda" en una escala superior a su instauración en Nueva España. Paralelamente, esta institución, junto con las "mercedes", fue una forma de retribución para los conquistadores, independiente del botín que significaron los repartos de Cajamarca y el Cuzco". Ídem, pág.: 41. 
el derecho de propiedad, sobre los territorios conquistados ${ }^{(12)}$, y así fue, el Papa Alejandro VI, a solicitud de los Reyes Católicos emitió una serie de bulas papales para legitimar, validar y legalizar la invasión y la apropiación de territorios en el Perú.

Al lado de las encomiendas y las mercedes, la esclavitud fue una práctica constante en nuestro país, y específicamente de forma abierta y franca en la región amazónica, la esclavitud formal no fue acogida por los virreyes, los criollos de Lima ni por los caciques, sin embargo la esclavitud real fue la que primaba sobre todo en las grandes haciendas y centros mineros de la costa, sierra y selva del Perú(13), hubo más de 300 años de esclavismo ${ }^{(14)}$, alentado por los encomenderos, las misiones religiosas, los hacendados, los jefes militares y los mineros. Por otro lado, las reducciones ${ }^{(15)}$ fueron prácticas comunes a lo largo y ancho del país, mediante las reducciones, los gamonales, caciques, hacendados, mineros y encomenderos, podían obtener un gran número de indígenas, fuerzas de trabajo, a la par, podían aculturarlos, enseñarles la palabra de dios, civilizarlos, enseñarles el idioma castellano, etc. Para escapar de las reducciones, y no ser encomendados, muchos indígenas comenzaron a negar su identidad y se creían mestizos, pues los mestizos no eran encomendables ${ }^{(16)}$.

(12) "Para tomar posesión del nuevo mundo Las Indias fueron consideradas Res nullius a pesar de estar habitadas. Y para que ningún otro pueblo cristiano se asentara en ellas los Reyes tuvieron que encontrar la manera de justificar la conquista y para ello recurrieron al denominado Título Pontificio. Es decir, solicitaron al entonces Papa Alejandro VI a que expidiera bulas, que eran el instrumento jurídico que ya había sido utilizado para legalizar algunas conquistas anteriores”. Extraído de: Harguindeguy, Juan Manuel, "Un Largo Camino Hacia el Reconocimiento de Derechos Indígenas”, Edit.: Universitat Pompeu Fabra, Barcelona, 2010, pág.: 5.

(13) "The elderly people in Diamante told stories of their grandparents working in slavery for the rubber bosses ... The Yine often worked as allies or intermediaries between the rubber entrepreneurs and the indigenous population and were accustomed to enslave other tribes but also suffered enslavement themselves". Extraído de: Opas, Minna, "Different but the Same, Negotiation of personhoods and Christianities in Western Amazonia", academic dissertation, Department of Comparative religion, University of Turku, Finland, 2008, pág.: 10.

(14) "Con estas leyes, el indio era requerido en castellano, muchas veces mientras huía, a que se haga cristiano y a aceptar la soberanía hispana. Si la aceptaba era luego sometido a la encomienda siendo teóricamente un súbdito libre de la Corona pero al mismo tiempo obligado a trabajar sin ser legalmente esclavo". Extraído de: Harguindeguy, Juan Manuel, "Un Largo Camino Hacia el Reconocimiento de Derechos Indígenas"..., pág.: 9. Además, cabe precisar que esta práctica esclavista siguió hasta 1854, año en que el presidente Ramón Castilla la abolió.

(15) "Esta política (se refiere a las reducciones) se inicia en 1550/1560 para Nueva España y a partir de 1570 se implementa en Perú... Consistió en el traslado forzoso de indígenas, muchas veces de distintas etnias, para reducirlos o agruparlos en pueblos. Estas reducciones se organizaron según los moldes castellanos y los indígenas que allí vivieron trabajaron en haciendas o chacras, minas o en el servicio personal. En cada reducción había una iglesia que sirvió para adoctrinar a los indígenas en la religión católica y cuyo mantenimiento estaba a cargo de los indios a través de tributos". Ídem, pág.: 10, lo entre paréntesis y cursiva es nuestro.

(16) "Los mestizos no podían ser encomendados con lo cual muchos indígenas buscaban deliberadamente diluir su identidad étnica y la de sus descendientes para librarse de ella". Ibídem. 
El régimen del vasallaje en la región amazónica, fue brutal, exterminador y radical. El régimen económico-social de los pueblos indígenas y de las tribus fue trastocado, por el impulso incesante de los invasores de obtener mercancías (sobre todo minerales como el oro y la plata) de forma rápida y violenta. A la par de ello, se les impuso una cultura, una religión, un idioma, un Estado y unas leyes que rompieron con su tradición ancestral y armónica con la naturaleza y el universo. Los que traían y transmitían directamente a las distintas etnias, todas estas ideologías, culturas e instituciones europeas fueron los encomenderos, los hacendados, los aventureros, los representantes de la corona, pero de sobre manera, los misioneros religiosos (los jesuitas, posteriormente en la época republicana los dominicos, los evangélicos, etc.), quienes inculcaban la palabra del señor, crearon escuelas de adoctrinamiento y sancionaban hasta con la muerte y/o la esclavitud las desobediencias y las herejías.

En el periodo de la República (1824 - actualidad), hubo ciertos cambios que favorecieron a los grupos indígenas, como la eliminación del trabajo forzado, el reconocimiento progresivo de sus derechos colectivos, la visibilización de estos grupos sociales alejados de las metrópolis, el inicio del reconocimiento de la identidad y cultura de estas etnias, etc. Sin embargo en los primeros años de la República estos grupos sociales seguían siendo tratados como inferiores, primitivos y salvajes, así como en el proceso de la construcción de un país independiente, no fueron tomados en cuenta, pues se impuso el Estado unitario, con una sola nación, un solo idioma, una religión, una educación castrense, etc., es decir, una vez expulsados los españoles, seguían los vestigios de la sociedad colonial, en lo económico, político, jurídico, administrativo y social.

El régimen económico del vasallaje se mantuvo hasta bien entrado el siglo XX, y era el régimen económico preponderante, de una parte había un señor gamonal o hacendado propietario de las tierras cultivables, del ganado, de los instrumentos de trabajo, etc. ${ }^{(17)}$, de otra parte estaba el trabajador de la tierra, el vasallo, que servía a su señor propietario de grandes extensiones de tierra, el siervo de la gleba que aunque poseía un pequeño terreno para su cultivo familiar, tenía sus aperos para sus trabajos agrícolas, estaba obligado a trabajar para el hacendado o gamonal. Este sistema económico fue más practicado en la costa y sierra del Perú, no tanto en la Amazonía, debido al difícil acceso al territorio selvático agreste y a la renuencia de los indígenas. Además, junto al régimen del vasallaje, sobrevivía

(17) "Durante todo el arco temporal que abarca desde 1530 hasta 1591 cuando se inician las "composiciones", este proceso va sentando las bases para la aparición de las haciendas. Las evidencias son claras en cuanto al hecho empírico de conjunción de terrenos para formar verdaderos latifundios: físicamente concentrada, en la tierra se incubó una institución con sus relaciones básicas de producción. Hubo un proceso genético paralelo a la concentración de la tierra, del que son "expresión" la forma de propiedad y el grado de división del trabajo y cooperación simple correspondiente". Extraído de: Noejovich, Hector, Salazar-Soler, Carmen y otros, "Compendio de Historia Económica del Perú", Tomo II: Economía del Periodo Colonial Temprano, Editor: Carlos Contreras, primera edición, Edit.: Banco Central de Reserva del Perú y el Instituto de Estudios Peruanos, Lima, 2009, pág.: 352. 
el régimen económico esclavista, y más tarde comenzó a extenderse el incipiente régimen económico capitalista.

Después de la época virreinal, la región amazónica no estaba extendidamente colonizada, como ocurrió con la costa y la sierra, por lo que, los primeros gobernantes de la República promovieron la colonización de esta parte del país, otorgando grandes facilidades a empresarios nacionales, pero sobre todo a los internacionales, para explotar los recursos naturales de esa zona, extender la presencia del Estado, "civilizar" a los indígenas, y de esta manera integrarlos coactivamente dentro de ciertos parámetros discriminatorios, homogéneos, bajo una sola cultura, una sola religión, un solo idioma, etc. En este proceso se exterminó a muchos pueblos indígenas, los que se oponían a una forma de organización económico-social distinta a la suya ancestral, tildados de salvajes y bárbaros opositores al desarrollo del país.

Junto al proceso de vasallaje, y al proceso de exterminio de aquellos que no aceptaban este nuevo régimen, se desarrollaba el proceso de expropiación ${ }^{(\mathbf{1 8})}$, expulsión de los indígenas de sus territorios ancestrales, muchos de ellos migraron obligadamente, en busca de sus medios de vida materiales, a los enclaves mineros, centros industriales, centros agroindustriales y a las ciudades, donde podían vender su fuerza de trabajo a cambio de un salario. De esta manera comenzaba a erigirse el régimen capitalista en territorio peruano.

El salario, la jornada de trabajo, la venta de la fuerza de trabajo, el dinero, la mercancía, la propiedad privada, el contrato laboral, etc., son categorías e instituciones propias del régimen económico capitalista. A fines del siglo XIX y comienzos del XX comenzaron a ingresar capitales europeos, sobre todo de Inglaterra, para concretar negocios en el país, ferrocarriles, carreteras, centros industriales, exportación de minerales, etc., y con ello se impulsó el régimen capitalista de producción, que para mediados del siglo XX ya era el régimen económico predominante en el Perú, desplazando al régimen del vasallaje, aunque este último era preponderante en algunas regiones del país hasta la reforma agraria de la década de 1970.

En la región amazónica, con la eliminación del esclavismo y del vasallaje, hubo la necesidad de contar con trabajadores asalariados para la explotación del caucho, la madera, el oro, etc. Los propios indígenas desplazados de sus territorios por las concesiones agroforestales, mineras y petroleras, conforman la mano de

(18) "En el escenario de la expansión acelerada del latifundio, cuando los propietarios de tierras iniciaron un proceso de agresión a las tierras vecinas, las composiciones se convirtieron en un mecanismo de legalización. El pago en dinero permitió convalidar usurpaciones de hecho, mucho más numerosas y extendidas que las que se registraron en el período inicial hasta las primeras Visitas, de 1594 hasta 1619. A nivel de los documentos locales, esta Visita ofrece las mismas características de abuso y despojo que exhibió el proceso abierto en todo el espacio peruano". Ídem, pág.: 429. 
obra para aquellas tareas, aunque por la gran demanda de trabajo, los empresarios trajeron trabajadores de otras latitudes del país, del norte, de Loreto y Ucayali, del sur, de Cusco, Arequipa y Puno, y de otras regiones, asegurándose tener la suficiente fuerza de trabajo para valorizar su capital.

Con la reforma agraria iniciada a fines de la década de 1970 se dieron mayores facilidades al capital para incursionar en casi todos los rubros de la economía nacional, y con ella se terminó de consolidar la acumulación originaria del capital, comenzada en el siglo XVI en el Perú. En la región amazónica se han desarrollado en gran medida, las industrias extractivas ${ }^{(19)}$, vale decir la minería, sector hidrocarburos y la maderera, y en menor medida el sector agrícola, pesquera y ganadera ${ }^{(\mathbf{2 0})}$. Todas estas actividades dentro del sistema productivo predominante no solo en el Perú, sino en el mundo, el régimen económico-social capitalista.

Los pueblos indígenas y las tribus, o las denominadas comunidades nativas, como se les conoce hoy en día, forman, directa o indirectamente, parte del régimen del capital. Su régimen económico fue violentado, sus instituciones y categorías económicas originarias fueron desplazadas por el dinero, el comercio, la jornada de trabajo, la venta de la fuerza de trabajo, la mercancía, la producción de valores, en dos términos, por el trabajo asalariado y el capital. Se exceptúan los pueblos indígenas en aislamiento voluntario, "no contactados", las etnias que viven aislados, quienes mantienen su régimen económico comunitario intacto, pero amenazado por el avance del capital en busca de petróleo, gas, oro u otros recursos naturales.

La gran mayoría de los pueblos indígenas o comunidades nativas de la región amazónica, conocidos y censados, son enclaves a los cuales alcanza y se extiende el régimen capitalista y se reproduce constantemente. Cuando tomamos conocimiento de que varios indígenas de diferentes comunidades nativas se dedican a la extracción del oro, a la explotación maderera o de que migran a los centros poblados por trabajo, entonces se confirma que el capitalismo está tomando fuerza cada vez más en la selva. Se aprecia el dinero, se legitima el trabajo asalariado, pasa por normal la propiedad privada capitalista, se deja de lado el idioma originario y cambian las conductas individuales y colectivas entorno al capital. Probablemente sea un proceso que todavía está en curso,

(19) "La PEA ocupada que tiene como lengua materna alguna lengua nativa, es absorbida mayormente por las ramas de actividad extractiva (52,2\%), en porcentaje bastante mayor que la PEA cuya lengua materna es el Castellano (20,4\%)". Extraído de: Suárez Rodríguez, Flor, Ruiz Calderón, Richard y otros, "Perú: Condiciones de Vida de la Población Según Origen Étnico", Instituto Nacional de Estadística e Informática, Lima, 2016, pág.: 77.

(20) "Según autopercepción de origen étnico, el 44,9\% de la PEA que se autoidentifica de origen nativo trabaja en actividades de agricultura, pesca y minería, le sigue a distancia el 14,9\% que se localiza en actividades económicas de comercio, un 6,9\% en manufacturas, $6,1 \%$ en otros servicios, $6,0 \%$ en construcción, 5,9\% en transportes y comunicaciones , 5,7\% en hoteles y restaurantes", ibídem. 
pero el desplazamiento territorial, la expropiación, la propiedad privada, el trabajo asalariado y el capital, presionan para terminar de transformar el régimen tradicional originario en régimen capitalista. Sin embargo, existen varios pueblos indígenas y tribales, organizaciones externas pro-indígenas, intelectuales, etc., que luchan, en diversos contextos, jurídico, político, económico y teórico, para hacer respetar sus territorios, su cultura, su identidad, su idioma y su ideología.

\section{El régimen económico actual del pueblo Harakbut}

El pueblo Harakbut es originario de la región de Madre de Dios, posiblemente el pueblo originario más antiguo de la cuenca del Madre de Dios ${ }^{(21)}$, migraron hace más de cinco mil años provenientes del alto río Madeira en Brasil, y actualmente ocupan los departamentos de Madre de Dios, Cusco y Puno. La palabra "Harakbut" se escribe como tal pero se pronuncia "Harakmbut". El término "Harakbut", "Harakmbut" o "Arakbut" significa gente, familia, humanidad"(22). Los Harakbut tienen una cosmovisión originaria particular del mundo, tienen una filosofía animista, sienten y piensan que las plantas, animales, seres humanos, la lluvia y demás fenómenos naturales tienen espíritu e interaccionan unos con otros $^{\text {(23) }}$. Los Harakbut creen en varios espíritus, el más poderoso es el "Toto", pero también están los "Dumberi", los "WuaWeri" y el "Wayorokeri"(24). Los Harakbut creen en el mito de creación del árbol del Wanamei, afirman que todos son hijos del Wanamei.

El pueblo Harakbut actualmente tiene una población aproximada de 1623 personas ${ }^{(\mathbf{2 5})}$, divididas en siete sub-grupos o parcialidades, distinguiéndose por algunos rasgos culturales, por variaciones dialectales, por rasgos físicos, por

(21) "En otro artículo (Moore, en prensa) avancé la hipótesis, basado en distancias lingüísticas, de que los Harakbut serían el pueblo originario más antiguo de la cuenca del Madre de Dios". Extraído de: Moore Huyett, Thomas Rutherford, "Los Harakbut, su territorio y sus Vecinos", Informe Pericial Antropológico presentado al Tribunal Constitucional del Perú, Lima, 2015, pág.: 2.

(22) "Pertenece a la familia etnolingüística Harakmbut con idioma propio 'Harakmbut hate' y su autodenominación «Harakmbut» significa "gente, familia, humanidad»". Extraído de: Gálvez Durand, Claudia, Corisepa Dreve, Rómulo y otros, "Reserva Comunal Amarakaeri - Plan Maestro 2008-2012", Edit.: Intendencia de Áreas Naturales Protegidas, Lima, 2008, pág.: 61.

(23) "Para el pueblo Harakmbut el mundo circundante es un espacio animado. Cada uno de los elementos que lo componen, tiene su propio espíritu animador. Las plantas, los animales, las personas y los distintos fenómenos que se sitúan en el espacio ecológico, poseen espíritus que toman la parte activa en las relaciones que tienen entre sí". Ibídem.

(24) "El espíritu más fuerte de todos es el Toto, quien juega un papel rector de la naturaleza. Los espíritus del monte son los Dumberi, fuertes, peligrosos y conformados por entes animadores de los animales y plantas de este medio. Los espíritus del río son los WuaWueri, menos fuertes y hasta benefactores, propios de los peces y el agua. El Wuayorokeri es el sabio y, en su trance shamánico, tiene visiones. Por ende, el Wuayorokeri es el conocedor del significado de los sueños. Conoce el poder que poseen los animales, las plantas y los elementos del medio que rodean la vida de las personas y su relación con el espíritu rector de todos, el Toto". Ibídem.

(25) Dato extraído de: Gálvez Durand, Claudia, Corisepa Dreve, Rómulo y otros, "Reserva Comunal Amarakaeri - Plan Maestro 2008-2012"..., pág.: 62. 
formas de vestirse y por variaciones en algunos usos y costumbres. Los siete subgrupos o parcialidades Harakbut son; los Arakbut o Amarakaeri ${ }^{(26)}$, los Arasaeri ${ }^{(27)}$, los Kisaberi ${ }^{(28)}$, los Pukirieri o Amaiweri ${ }^{(29)}$, los Sapiteri o Sirineri ${ }^{(\mathbf{3 0})}$, los Toyeri ${ }^{(\mathbf{3 1})}$ y los Wachiperi ${ }^{(32)}$. El ámbito de sus actividades abarca los ríos; Eori (Madre de Dios), Karene (Colorado), Kipodwe, Wandakwe, Ishiriwe (Chilive), Inambari, Arasa, San Gaban, Huarihuari, Challuma, Wepetwe (Huepethue), Pukiri, Wasorokwe (Huasoroco), Alto Madre de Dios, Marcapata, Manu, Queros, Q'osñipata, Pilcopata, Tono y Piñipiñi.

El Wadari ${ }^{(33)}$ o territorio de los Harakbut es un concepto distinto al europeo, pues el territorio para este pueblo indígena es todo el espacio que los rodea, la naturaleza, el espacio donde viven y han vivido sus antepasados, el lugar de pesca, de caza, de recolección, donde obtienen su medicina, el lugar donde producen sus instrumentos de trabajo, de donde obtienen los materiales para construir sus viviendas, el espacio donde se han desarrollado económica, política y socialmente y han edificado una cultura. Los Harakbut creen que el territorio es parte de ellos y que ellos son parte de ese territorio, y que en conjunto forman parte de la naturaleza, única e indivisible ${ }^{(34)}$. El concepto de territorio para los Harakbut es relativo, amplio y elástico ${ }^{(35)}$, no se asemeja al concepto europeo de territorio vinculado al de propiedad privada ${ }^{(36)}$, es más, los Harakbut no consideran que el espacio que ocupan les pertenezca, e históricamente se conoce que los Harakbut han compartido sus territorios con otras tribus ${ }^{(37)}$.

Durante la época precolombina, los Harakbut realizaron intercambios de algunos productos con varias otras culturas, desde el primer milenio

(26) Con presencia actual en las comunidades nativas de: Puerto Luz, San José del Karene, Barranco Chico, Boca del Inambari, Shintuya y Masenawa.

(27) Con presencia actual en la comunidad nativa de Arasaeri de Villa Santiago.

(28) Con presencia actual en la comunidad nativa de Boca Ishiri.

(29) Con presencia actual en la comunidad nativa de Kotsimba.

(30) Con presencia actual en las comunidades nativas de: Boca Ishiri y Pukiri.

(31) Con presencia actual en la comunidad nativa de Shintuya.

(32) Con presencia actual en las comunidades nativas de: Queros, Santa Rosa de Huacaria, Shintuya, Diamante y Puerto Azul.

(33) "El concepto de territorio, entre los Harakbut se expresa con la palabra Wadari, que quiere decir tierra, terreno, suelo, mundo (Tripp 1995:112), es decir el espacio de ocupación humana". Extraído de: Moore Huyett, Thomas Rutherford, "Los Harakbut, su territorio y sus Vecinos"..., pág.: 3.

(34) "... en términos de una visión social de la naturaleza, donde no cabe la distinción del hombre como miembro de una sociedad y la tierra como parte de la naturaleza. Es así, tanto los Harakut como los elementos de la naturaleza - tangible e intangible - uno solo, el territorio Harakbut". Ídem, pág.: 4.

(35) "Los límites territoriales de los Harakbut deben verse como elásticos, afectados por los avances y retrocesos de los frentes externos que presionan sobre ellos, pero siempre identificados con ellos, así sean espacios compartidos". Ibídem.

(36) "el concepto occidental de propiedad alienable, hipotecable, embargable y prescriptible es ajeno e imposible. Su territorio es integral para y con ellos y no puede separarse de ellos". Ibídem.

(37) "en diferentes momentos históricos se encuentran presencias Ese eja, Matsigenka, Iñapari, Yine y "Mashco Piro" ocupando espacios al interior del territorio mayor Harakbut y presencias Harakbut al interior de los territorios mayores de esos pueblos". Ibídem. 
de la era cristiana, primero con los Wari y los Tiwanaku, luego con los Qolla, y después con los Inkas ${ }^{(38)}$. Los Inkas tuvieron contacto con varias tribus, no solo con el pueblo Harakbut, sino también con los Yine y los Matsigenka. A las tribus ubicadas en las cuencas de los ríos Urubamba y Apurímac, los Inkas los denominaban "Antis"(39). Los Inkas efectuaron varios viajes exploratorios al "Antisuyo", por ejemplo, el realizado por el Inka Yawar Waqaq con quince mil hombres. Los Inkas Ilegaron hasta el rio "Amarumayo", territorio ancestral de los Harakbut, lo que para los indígenas Harakbut es el rio “Eori” (rio Madre de Dios).

En la época virreinal, las primeras expediciones hacia la región amazónica fueron realizadas en el siglo XVI. Los invasores españoles buscaban territorios para asentarse, colonizar y crear enclaves minero-auríferos, agroforestal, extracción maderera, caucho, etc., sin embargo, encontraron resistencia de los pueblos originarios de esos lugares. Durante el transcurso de la época colonial hubieron varios enfrentamientos, unos más violentos y sangrientos que otros ${ }^{(\mathbf{4 0})}$. Algunas veces encontraban resistencia y oposición de los jefes de las tribus, frente a tal situación, los colonizadores mandaban a ejecutar a los líderes ${ }^{\mathbf{( 4 1 )}}$ y a todo aquel indígena que se rehusaba a trabajar en los enclaves extractivos.

En los inicios de la época republicana los gobernantes impulsaron la colonización de la selva peruana, como Agustín Gamarra ${ }^{(42)}$ y Ramón Castilla ${ }^{(43)}$. En el proceso exploratorio y colonizador en la región de Madre de Dios hubo una política abierta y franca de exterminar a todo aquel que se opusiera a los planes económicos, políticos y sociales de los invasores, un ejemplo de ello fue la matanza de varios indígenas Harakbut, realizado por Carlos Fermín

(38) "Patricia Lyon (1981) precisa las zonas de intercambio de bienes entre los Inkas y los pueblos originarios de las cuencas de los ríos Apurimac, Urubamba, Paucartambo, Alto Madre de Dios e Inambari. Todos estos sitios de intercambio se ubican por encima de los 2,000 msnm". Ídem, pág.: 5.

(39) "Antis era el término genérico empleado por los Inkas para referirse a los pueblos de las cuencas del Urubamba y Apurímac"

(40) "Ios colonos de Q'osñipata comenzaron a protestar y a hablar de los ataques por los pueblos originarios (Lyon 1995)...." Ídem, pág.: 8.

(41) "A principios del siglo XVIII, el capital y gobernador de Paucartambo, Tiburcio Landa, organizó una expedición militar que entró hasta el pongo de Q'oñeq y mató a un "huairi" provocando la hostilidad de "los indios" (García Rosell 1905:12). El empleo del término Wa iri, que en el idioma Harakbut significa una persona de prestigio o, vulgarmente, "jefe, amo, curaca, patrón" (Tripp 1995:116)". Ídem, pág.: 9.

(42) "Gamarra mandó la primera expedición militar peruana al valle de Q'osñipata en apoyo a los hacendados cocaleros allí (Sala i Vila 1998:410). Después, como presidente, en 1832, incentivó la colonización de la selva mediante una ley que otorgaba propiedades que habían sido de realistas a extranjeros que las ocuparan y redujeran a los pueblos originarios (García Jordán 1995:14)". Ídem, pág.: 10.

(43) "En este contexto el presidente Ramón Castilla, 1845-1854 y 1854-1862, se ocupaba del desarrollo del interior del país, enfocado la Amazonía por lo que implicaba en cuanto acceso al Atlántico y el comercio con Europa. Para ello comenzó a promover la exploración y colonización de la Selva en alianza con interés europeos". Ídem, pág.: 12-13. 
Fitzcarrald y sus acompañantes ${ }^{(44)}$, así como por Nicolás Suárez ${ }^{(45)}$ y por el ingeniero Sven Ericsson ${ }^{(46)}$.

Para concretar el proceso colonizador con éxito, era necesario el adoctrinamiento religioso. Fue este elemento religioso, el que permitió sojuzgar a los pueblos originarios, dotando a los hacendados y capitalistas de mano de obra sumisa, obediente y disciplinada. De otro lado, los religiosos inculcaron la creencia en Dios, todopoderoso, omnipresente y omnicomprensivo, prohibiendo las prácticas ancestrales que se oponían al nuevo Dios. Estaban negadas las ceremonias ancestrales, el reconocimiento y respeto a los espíritus de la montaña, de los ríos, de los animales, de las plantas y árboles, estaba vetada la reproducción de los vínculos ancestrales con los espíritus sagrados del bosque y el respeto a la madre naturaleza. Las denominadas "misiones"(47) de los religiosos en la región amazónica, trajeron toda una carga cultural y religiosa que debían de imponer, a cualquier precio, a los "salvajes", a los "indios sin alma", a los "incivilizados". Primero fueron las misiones de los jesuitas, después de los dominicos y franciscanos, hoy en día, en las comunidades nativas, están presentes varias sectas o corrientes religiosas. Está documentado, por ejemplo, el actuar de los padres dominicos, quienes primero se asentaban en una zona estratégica, ostentaban haciendas, instalaban escuelas donde solo se enseñaba en español, daban a los indígenas instrumentos

(44) "señores de la parte oriental del istmo, alarmados con aquella multitud de hombres del Ucayali, que invadían sus dominios, y "temerosos del contagio de catarro", enviaron una embajada para pedirles a la gente de Fitzcarrald que no siguieran adelante, lo que Fitzcarrald no estaba dispuesto a aceptar. Rechazada su petición, los Mashcos se retiraron para movilizar a los suyos, aliados con otro pueblo, residente en el bajo río Manu y los ríos Madre de Dios y Karene (Colorado). Pero Fitzcarrald también movilizó a unos 1,500 hombres, entre los Asháninka y Yine que le acompañaron y los caucheros mestizos, y efectuaron correrías sangrientas en las Quebradas Sahuinto, Sotlija, Fierro, Cumerjali y todo el Manu, masacrando a cientos de hombres de ese grupo y capturando mujeres y niños como esclavos". Ídem, pág:: 20.

(45) "Así, Nicolás Suárez aprovechó su sociedad con Fitzcarrald para reclamar derechos sobre gran parte del territorio peruano del Madre de Dios y comenzó a realizar correrías hacia el río Inambari, donde sus empleados mataban a muchos varones y pagaban entre 200 y 400 soles por cada individuo de los Ese eja y Harakbut Arasaeri sobrevivientes capturado, para llevarlos a Bolivia para el trabajo en sus gomales". Ídem, pág.: 21.

(46) "... Ericsson respondió: "una vez establecido el campamento central en la boca de Colorado, con su campamento de aterrizaje, estación de radio y demás implementos para la colonia, emplearemos elementos modernos para producir en las tribus insumisas una impresión de desconcierto terror, que contenga sus ímpetus criminales. Haremos un raid con aeroplanos, llevando bombas de gases lacrimosos que al expandirse en las selvas y provocar fuerte lagrimeo en los mashcos, que sientan que algo superior les invade en castigo de sus horribles crímenes. En caso de ataque al campamento, nos defenderemos con la guardia militarizada, que nos acompañará, guardia que desde luego facilitará el Gobierno, tratándose de una empresa de tan grandes expectativas nacionales...". Ídem, pág.: 35.

(47) "... Una vez rendidas las tribus o atemorizadas por los procedimientos dichos, contamos con la labor altamente civilizadora de los Misioneros. Ellos con conocimiento del idioma que ya poseen, y con sus métodos persuasivos de atracción, son los llamados a transformar su mentalidad primitiva y reaccionaria, bajo la acción de la Escuela y de la Iglesia, haciéndoles útiles a la colonización misma y al país". Ídem, pág.: 36. 
de trabajo y medicamentos a cambio de jornadas de trabajo intensas ${ }^{(\mathbf{4 8})}$.

Actualmente, el territorio de los Harakbut, así como el de otros pueblos indígenas como los Yine y los Matsigenka, se ha reducido, y se sigue reduciendo, debido, principalmente, a la expansión de los colonos, a las concesiones otorgadas por el Estado (relacionadas al petróleo, gas y actividades mineras) y a otras personas que laboran informalmente en distintos rubros de la economía vinculadas a la extracción del oro, la explotación maderera y agroindustrial. Moore afirma que el territorio histórico de los Harakbut de más de 2' 962,000 hectáreas se ha reducido considerablemente ${ }^{(49)}$. Este proceso de reducción del territorio ancestral de los Harakbut y de otros pueblos originarios, los desplazamientos, las expropiaciones, las privatizaciones progresivas y la incursión del capital, amenazan, con más intensidad y constancia, el territorio, la cultura, el idioma y, sobre todo, la vida de los propios indígenas.

El régimen económico preponderante, actualmente, en el territorio que ocupan los Harakbut está entre el régimen económico-social de la comunidad ancestral y el régimen económico-social capitalista. Las diferentes formas de organización económica, política y social de las personas que habitan esos territorios se pueden encontrar dentro de los parámetros entre el régimen de la comunidad ancestral y el régimen capitalista. La vinculación, más o menos, de los indígenas con el dinero, las mercancías, el trabajo asalariado, el capital, la propiedad privada, la jornada de trabajo y otras categorías de la economía capitalista, marcan el cambio del régimen de la comunidad ancestral al régimen del capital. Y con el cambio de un régimen a otro, cambia también la cultura, la percepción y la filosofía que se tiene del mundo, el idioma, las costumbres, la forma de vestirse, las instituciones políticas y jurídicas, en resumen, cambia la forma de vida del ser humano en sociedad. Deja de ser importante la naturaleza, la cultura, la propiedad colectiva, preservar el idioma, y cobra importancia el dinero, la valorización del capital, la ganancia, la explotación irracional de la naturaleza, la extracción de petróleo y el oro. Es todo un proceso histórico de cambio a nivel de la organización del trabajo, de la producción, de las relaciones entre las personas entorno a la producción, de

\footnotetext{
(48) "Los misioneros dominicos adoptaron un modelo de hacienda española para sus misiones, al borde de un río navegable o con acceso a carreteras, y juntaban pueblos de diferentes sub-grupos y también diferentes etnias en la misma misión. Allí establecieron escuelas de internado que sólo enseñaban en español en un intento de debilitar tanto el idioma como la cultura y lograr que sus recogidos se integren a la cultura occidental e hispano-hablante, dejando atrás lo propio. Ofrecían herramientas de metal y otros bienes comerciales en sus tiendas y servían de intermediarios entre los pobladores originarios del entorno de la misión y el mundo externo. Entre otros bienes de consumo, vendían medicamentos, endeudando a estos pobladores que luego eran obligados a trabajar para saldar las cuentas....' Ídem, pág.: 39.

(49) Moore afirma que, actualmente, el "total territorio indígena es de 709,494.06 hectáreas ... así aproximadamente el $24 \%$ del territorio ancestral Harakbut se puede considerar como todavía territorio de cuatro pueblos indígenas diferentes, mientras que el $76 \%$ se encuentra en manos de personas no indígenas". Ídem, pág.: 48.
} 
las instituciones políticas y jurídicas, de la cultura y de la filosofía, que ocurrió y que sigue ocurriendo en nuestros días.

En los pueblos indígenas en aislamiento, sin contacto con las ciudades y centros poblados, rige el régimen económico de la comunidad ancestral, la caza, la pesca, la recolección y la agricultura a pequeña escala. En estas comunidades se mantiene intacta la cultura ancestral, las costumbres tradicionales, las instituciones políticas, el idioma, la propiedad colectiva de la tierra, la relación milenaria entre el ser humano y la naturaleza, la división social del trabajo, etc. Estos pueblos se ubican en zonas muy alejadas de los centros poblados y de las ciudades, se desplazaron hasta estos lugares remotos debido a la presión de los colonos y los capitalistas petroleros, auríferos y forestales, que invaden cada vez más sus territorios, contaminando sus aguas y alejando los animales de caza.

En las com unidades nativas cercanas a los centros poblados y a las ciudades, la economía se basa en el trabajo asalariado, el intercambio de mercancías, el dinero, la extracción de oro, la explotación maderera y en la propiedad privada capitalista, pero también aun sobrevive la caza, la pesca, la recolección y la crianza de animales menores. En estas comunidades nativas se vive en el día a día, una transformación del régimen de la comunidad ancestral al régimen capitalista. Aquí, los propios indígenas laboran en la extracción aurífera, en la explotación maderera y otras actividades relacionadas, a veces lo hacen organizados en familias, otras veces se agrupan en comunidades y las más de las veces la realizan privadamente, adquiriendo las fuerzas de trabajo de los colonos, de personas migrantes, de extranjeros y muchas veces de los propios indígenas.

En las comunidades nativas relacionadas directamente con los centros poblados y con las ciudades, incluso aquellas comunidades nativas que se transformaron en centros poblados o en pequeñas ciudades, el régimen del capital ha ganado la batalla al régimen de la comunidad ancestral. La actividad extractiva aurífera, forestal, y otras actividades relacionadas, a gran escala, marcan el inicio del régimen de producción capitalista. En este régimen aparecen con mucha claridad las categorías personificadas del capitalista y del trabajador asalariado, así como de la propiedad privada capitalista, el dinero, la mercancía, el proceso de trabajo, el proceso de valorización, la acumulación del capital, la reproducción a escala ampliada del capital, y el sacrosanto principio de la valorización del capital.

El pueblo Harakbut está sufriendo los embates del capital, la incursión de colonos en busca de oro y otros minerales, la expropiación de territorios ancestrales y el desplazamiento de indígenas. Al respecto podemos leer en el Plan Maestro de la Reserva Comuna Amarakaeri: "... el año 1993 y 2005, el Centro Poblado de Boca Colorado ha casi duplicado su población, siendo uno de los centros poblados con mayor población dentro de la zona de amortiguamiento debido principalmente 
a que en su jurisdicción se desarrollan actividades mineras"(50), más adelante también se puede leer: "Asimismo, en los últimos años se han creado nuevos centros poblados cuya actividad principal gira en torno a la actividad minera, siendo el Centro Poblado Pukiri / Delta I el que cuenta con la mayor cantidad de población (5 000 habitantes)"(51).

\section{La Federación Nativa del Río Madre de Dios y Afluentes (FENAMAD) vs Hunt Oil Company, Repsol Exploración y Pluspetrol Corporation}

Uno de los conflictos más relevantes actualmente en el Perú es el caso de la Federación Nativa del Río Madre de Dios y Afluentes (FENAMAD) vs Hunt Oil Company, Repsol Exploración y Pluspetrol Corporation. Veamos resumidamente de que se trata este conflicto, sus antecedentes fácticos, el Proceso Constitucional de Amparo y la pendiente Consulta Previa.

\subsection{Antecedentes del conflicto.}

En fecha 06 de octubre del 2005, el gobierno peruano, representado por el Presidente de la República, el Ministerio de Energía y Minas así como por el Ministerio de Economía y Finanzas, promulgan el Decreto Supremo № 0352005-EM, mediante el cual se ratifica la conformación, extensión, delimitación y nomenclatura del área inicial del Lote 76, adjudicándolo a Perupetro S.A. para la suscripción del Contrato de Licencia para la Exploración y Explotación de Hidrocarburos en el Lote 76. Además, se aprueba el Contrato de Licencia para la Exploración y Explotación de Hidrocarburos en el Lote 76 a celebrarse entre Perupetro S.A. y Hunt Oil Company (Block 76) of Perú L.L.C., Sucursal del Perú y, finalmente, se autoriza a Perupetro S.A. suscribir con Hunt Oil Company (Block 76) of Perú L.L.C., Sucursal del Perú el Contrato de Licencia para la Exploración y Explotación de Hidrocarburos en el Lote 76. Este Lote está ubicado en la Reserva Comunal Amarakaeri (RCA), territorio ancestral del pueblo Harakbut y en menor proporción de los pueblos Yine y Matsigenka, es decir, este Lote petrolero y gasífero 76 se superpone al territorio ocupado históricamente por dichos pueblos originarios.

En fecha 02 de mayo del 2006, se eleva a Escritura Pública el Contrato de Licencia para la Exploración y Explotación de Hidrocarburos en el Lote 76 entre Perupetro S.A. y Hunt Oil Company (Block 76) of Perú L.L.C., Sucursal del Perú. Este Contrato permite realizar a Hunt Oil Company (Block 76) of Perú L.L.C., Sucursal del Perú, una serie de operaciones con el objetivo de explorar y explotar hidrocarburos en un área de 1'434,059.869 hectáreas, que comprende las provincias de Manu y Tambopata (Madre de Dios), Paucartambo y Quispicanchis (Cusco) y Carabaya

(50) Gálvez Durand, Claudia, Corisepa Dreve, Rómulo y otros, "Reserva Comunal Amarakaeri Plan Maestro 2008-2012"..., pág.: 68.

(51) Ibídem. 
(Puno), espacio que abarca el territorio ancestral del pueblo Harakbut, y en menor proporción de los pueblos Yine y Matsigenka. Este hecho afectaría a los pueblos Harakbut, Yine y Matsigenka, a sus territorios ancestrales, al normal desenvolvimiento de sus vidas, a su cultura, a sus medios materiales de vida, a su relación con la naturaleza y su cosmovisión, a su identidad, a su libre y autónomo desarrollo político, económico, social, etc., a su libre disponibilidad de sus tierras y recursos, etc.

Aquel Contrato de Licencia para la Exploración y Explotación de Hidrocarburos en el Lote 76, contemplaba originalmente como plazos, los siguientes:

a) 7 años para la fase de exploración.

b) 30 años para la fase de explotación del petróleo.

C) 40 años para la fase de explotación del gas natural.

d) Adicionalmente a ello se suman los periodos (entre 5 y 10 años) de retenciones por diversas razones, por ejemplo el plazo para la búsqueda de mercados, el plazo para abrir vías de comunicación para posibilitar la extracción de los hidrocarburos a la costa peruana, etc.

En fecha 10 de noviembre del 2006 se modifica el Contrato de Licencia para la Exploración y Explotación de Hidrocarburos en el Lote 76, mediante el cual se realiza la cesión de posición contractual a favor de Repsol Exploración Perú, Sucursal del Perú, es decir Hunt Oil Company cede el 50\% de participación en el Contrato a favor de Repsol Exploración Perú. Mediante Decreto supremo 053-2006EM, se aprueba la cesión de posición contractual y se suma a Repsol Exploración Perú en el contrato inicial.

En fecha 25 de octubre del 2007, Hunt Oil Company (Block 76) of Perú L.L.C., Sucursal del Perú modifica su denominación social de: HUNT OIL COMPANY (BLOCK 76) OF PERU L.L.C., SUCURSAL DEL PERU a: HUNT OIL EXPLORATION AND PRODUCTION COMPANY OF PERU L.L.C., SUCURSAL DEL PERU. Esta modificación se debe a que, como veremos más adelante, Hunt Oil Company pretende incorporar a otra empresa de los mismos propietarios con similar denominación.

En fecha 08 de abril del 2014 se modifica nuevamente el Contrato de Licencia para la Exploración y Explotación de Hidrocarburos en el Lote 76, mediante el cual se realiza la segunda cesión de posición contractual, esta vez a favor de Pluspetrol Perú Corporation S.A., es así que, Hunt Oil Exploration and Production Company of Perú L.L.C., Sucursal del Perú cede el 15\% de participación en el Contrato a favor de Pluspetrol Perú Corporation S.A., además Repsol Exploración Perú, Sucursal del Perú también cede el 15\% de participación en el Contrato a favor de Pluspetrol Perú Corporation S.A. Esta segunda modificación del Contrato se realiza Mediante Decreto supremo 010-2014-EM. 
En fecha 22 de enero del 2015 se modifica por tercera vez el Contrato de Licencia para la Exploración y Explotación de Hidrocarburos en el Lote 76, mediante el cual se realiza la tercera cesión de posición contractual, esta vez a favor de Hunt Oil Company of Perú L.L.C., Sucursal del Perú, es así que, Hunt Oil Exploration and Production Company of Perú L.L.C., Sucursal del Perú cede el 33\% de participación en el Contrato a favor de Hunt Oil Company of Perú L.L.C., Sucursal del Perú. Esto se efectúa mediante Decreto supremo 045-2014-EM.

Entonces, resumiendo todas las posiciones contractuales realizadas, podemos afirmas que, actualmente en el lote 76 están cuatro empresas como contratistas:

1) HUNT OIL EXPLORATION AND PRODUCTION COMPANY OF PERU L.L.C., SUCURSAL DEL PERU con 2\% de participación.

2) REPSOL EXPLORACION PERU, SUCURSAL DEL PERU, con 35\% de participación.

3) PLUSPETROL PERU CORPORATION S.A. con 30\% de participación.

4) HUNT OIL COMPANY OF PERU L.L.C., SUCURSAL DEL PERU con $33 \%$ de participación.

En fecha 03 de agosto del 2015, mediante Decreto Supremo 025-2015-EM, se prorroga la fase de exploración por 3 años adicionales, que se computará a partir del 04 de agosto del 2015 hasta el 04 de agosto del 2018. Dicha ampliación de tres años adicionales, se divide en dos partes:

a) Primera parte, con una duración de 2 años (de agosto 2015 a agosto del 2017). En este periodo se realizarán diversas evaluaciones del pozo que se perforó, denominado pozo Dahuene $1 \mathrm{X}$, se realizarán análisis bioestratigrafico, análisis de apatita, medida de radiometría, reprocesamiento de líneas sísmicas seleccionadas, etc.

b) Segunda parte, con una duración de 1 año (de agosto 2017 a agosto 2018). En este periodo se realizarán diversos trabajos de campo y se perforará un pozo exploratorio de no menor de 3500 metros o 50 metros en el precretaceo.

En fecha 24 de mayo del 2016 se realizó la sustitución de los anexos A y $B$ del Contrato, es decir, se han hecho sueltas de áreas quedando de la siguiente manera:

1. Área original del Contrato (2006)

2. Suelta del $25.30 \%$ del área (2011)

3. Suelta del $16.32 \%$ del área (2015)

Área actual bajo Contrato $58.38 \%$
1'434,059.869 ha.

$362,769.786$ ha.

$234,052.300$ ha.

$837,237.783$ ha. 
El pueblo Harakbut, mediante su organización indígena denominada Federación Nativa del Río Madre de Dios y Afluentes (FENAMAD), desde la década de 1980, buscó el reconocimiento legal y protección, por parte del Estado, de sus tierras ancestrales. Es así que en el año 1998 "se constituye el Comité Pro-Reconocimiento y Gestión de la RCA, conformado por dos delegados de las comunidades de San Miguel de Shintuya, Shipetiari, Diamante, Boca Isiriwe, San José de Karene, Puerto Luz y Barranco Chico, así como por representantes de la FENAMAD y del Consejo Harakmbut Yine Matsiguenka - COHARYIMA"(52). Después de 12 años de evaluaciones, reuniones, pericias, etc., en el año 2000, se "... establece por Decreto Supremo № 028-2000-AG, la Zona Reservada Amarakaeri, sobre una superficie de 419 139,00 hectáreas"(53). Y, finalmente, en el año 2002 “... se categoriza la Zona Reservada como Reserva Comunal Amarakaeri por Decreto Supremo № 031-2002AG, el 9 de mayo de 2003, sobre una superficie de 402335.62 hectáreas" ${ }^{\prime(54)}$.

El objetivo de la creación y preservación de la Reserva Comunal Amarakaeri es"contribuir a la protección de las cuencas de los ríos Eori/Madre de Dios y Karene/ Colorado, asegurando la estabilidad de las tierras y bosques y manteniendo la calidad y cantidad de agua, el equilibrio ecológico y un ambiente adecuado para el desarrollo de las comunidades nativas Harakmbut" ${ }^{\prime(55)}$.

En nuestros días, la Reserva Comunal Amarakaeri se extiende sobre la mayor parte del territorio ancestral del pueblo Harakbut. En estas tierras, persiste aún la tradición de los Harakbut, sus costumbres, el equilibrio entre el ser humano y la naturaleza, el respeto por la vida, por el bosque, por los animales y las plantas, se mantiene y preserva las instituciones políticas, las relaciones económicas, la identidad, la cultura, el idioma y la forma de organización social ancestral. Sin embargo, el avance de los colonos, de los capitalistas petroleros, auríferos y forestales, resquebraja cada vez más los cimientos de una cultura milenaria, desplaza a los indígenas de sus territorios, los expropian, contaminan el agua, el suelo, el aire, ahuyentan a los animales, los indígenas, en muchos casos, se ven obligados a migrar a la ciudad y vender su fuerza de trabajo a cambio de un salario irrisorio, y en algunos otros, inician pequeñas empresas formales o informales de extracción del oro y otros minerales, así como de la explotación maderera.

\subsection{El Proceso de Amparo.}

En fecha 09 de setiembre del 2009, FENAMAD, en representación de las comunidades indígenas Harakbut, Yine y Matsigenka afectadas y/o amenazadas por las diferentes operaciones (perforaciones, líneas sísmicas, instalación de

(52) Gálvez Durand, Claudia, Corisepa Dreve, Rómulo y otros, "Reserva Comunal Amarakaeri Plan Maestro 2008-2012", Edit.: Intendencia de Áreas Naturales Protegidas, Lima, 2008, pág.: 25.

(53) Ibídem.

(54) Ílem, pág.: 26.

(55) Ídem, pág.: 30 
campamentos, utilización de químicos, construcción de helipuertos, zonas de descarga, etc.) en sus tierras, autorizadas mediante el Contrato de Licencia para la Exploración y Explotación de Hidrocarburos en el Lote 76, interpone Demanda Constitucional de Amparo contra Hunt Oil Exploration and Production Company of Perú LLC Sucursal del Perú, Repsol Exploracion Perú Sucursal del Perú y Peru Petro S.A., ante el Juzgado Mixto de Tambopata, Madre de Dios, y se tramita con número de expediente 267-2009.

Después de varias resoluciones de improcedencia, resoluciones de inadmisibilidad, apelaciones, etc., en fecha 17 de marzo del 2011 se admite, finalmente, la Demanda Constitucional de Amparo. Además, se planteó una Medida Cautelar de No Innovar, solicitando la suspensión de las operaciones de pruebas sísmicas 2D y otras, hasta que exista un pronunciamiento final de los Magistrados, la que fue declarada improcedente, se apeló dicha Resolución de improcedencia, y la instancia superior confirma la improcedencia.

En fecha 22 de agosto del 2014 el Juzgado Mixto de Tambopata emite Sentencia, declarando Infundada la Demanda, denegándose el petitorio de FENAMAD. Dicha sentencia es apelada y la Sala Mixta de Madre de Dios, en fecha 21 de enero del 2015 emite Sentencia de Vista, Confirmando la Sentencia de Primera Instancia, pero reconoce el Derecho de las comunidades indígenas, que se encuentran dentro, o adyacentes, de la Reserva Comunal Amarakaeri y que se vean afectadas por el proyecto petrolero, a ser consultadas.

En fecha 11 de febrero del 2015 se interpone Agravio Constitucional, que es un recurso impugnatorio de última instancia en el ámbito jurisdiccional peruano. Actualmente el proceso de Amparo está en el Tribunal Constitucional y se tramita bajo el expediente $N^{\circ}$ 02268-2015. El Tribunal Constitucional, lamentablemente, y no entendemos porqué, no se ha pronunciado hasta la fecha, esperemos que lo haga en el lapso más breve posible, teniendo en cuenta que la fase de exploración se ha prorrogado tres años más, hasta el año 2018, existiendo la posibilidad real de afectar varios derechos de los pueblos Harakbut, Yine y Matsigenka.

\subsection{La Consulta Previa.}

La Sentencia de Vista de la Sala Mixta de Madre de Dios, como ya mencionamos líneas arriba, reconoce el Derecho de los pueblos Harakbut, Yine y Matsigenka a ser consultados, de manera libre, previa e informada, con el objetivo de determinar si los derechos y/o los intereses de los pueblos Harakbut, Yine y Matsigenka serían perjudicados, y en qué medida, por el proyecto petrolero del Lote 76 ubicado en la Reserva Comunal Amarakaeri, territorio histórico de los Harakbut.

Por lo tanto, queda la tarea pendiente, por parte del Estado Peruano, de realizar el Proceso Administrativo de la Consulta Previa. La Consulta Previa está 
regulada por la Ley N²9785, Ley del Derecho a la Consulta Previa a los Pueblos Indígenas u Originarios, reconocido en el Convenio 169 de la Organización Internacional del Trabajo (OIT), por su Reglamento, el Decreto Supremo $N^{\circ} 001-$ 2012-MC, y a nivel internacional, por el Convenio $N^{\circ} 169$ de la OIT sobre Pueblos Indígenas y Tribales en Países Independientes (instrumento jurídico vinculante para nuestro país), así como por la Declaración de las Naciones Unidas sobre los Derechos de los Pueblos Indígenas.

Finalmente, debo decir que es una total falta de respeto a los pueblos indígenas, en general, y a los pueblos Harakbut, Yine y Matsigenka, en especial, un acto discriminatorio continuo, pero sobre todo es una grave violación del derecho de los pueblos indígenas a ser consultados, de manera libre, previa e informada, respecto de los proyectos extractivos que se pretenden desarrollar en sus territorios, así como también es una vulneración a los derechos de los pueblos indígenas de participar en los diferentes niveles de gobierno, tanto en el ámbito administrativo como legislativo, en los asuntos que afecten los derechos y/o los intereses de los pueblos indígenas, de decidir sus prioridades, de controlar su propio desarrollo político-económico, de preservar el medio ambiente que ocupan, de conservar sus costumbres e instituciones propias, de participar activamente en la elaboración y determinación de los proyectos de diferente índole que les conciernan, etc. Situación que debería corregir el gobierno lo más pronto posible, para salvaguardar los derechos de los pueblos indígenas.

\section{La resistencia del pueblo Harakbut.}

Con la llegada de los invasores españoles a las tierras de los diferentes pueblos indígenas, se inició la explotación del oro y la plata, el exterminio aborigen y el trabajo forzado ${ }^{(56)}$. Sin embargo, hubo una gran resistencia a ser sometidos bajo el nuevo régimen económico de opresión, y en muchos casos de esclavitud, sobre todo del pueblo Harakbut.

Los Harakbut fueron uno de los últimos pueblos indígenas en ser contactados y asimilados al mundo globalizado, es a fines a la década de 1940 donde recién se toma conocimiento de la existencia de varios subgrupos de los Harakbut, mientras que desde el siglo XVII, ya se conocía y se tenía contacto con otros pueblos indígenas, como los Yine y los Matsigenka. Es de resaltar la resistencia y la lucha de los Harakbut por mantener sus tradiciones, su cultura

(56) "el descubrimiento de los yacimientos de oro y plata de América, la cruzada de exterminio, esclavización y sepultamiento en las minas de la población aborigen, el comienzo de la conquista y el saqueo de las Indias Orientales, la conversión del continente africano en cazadero de esclavos negros: son todos hechos que señalan los albores de la era de producción capitalista". extraído de: Marx, Karl, “El Capital, Crítica de la Economía Política", Tomo I: El Proceso de Producción del Capital, Edit.: Lito Ediciones Olimpia S.A., México D. F., 1980, pág.: 638. 
milenaria, sus territorios ancestrales, su régimen económico tradicional, su idioma, su cosmovisión, etc., por muchos años, hasta la actualidad.

La resistencia del pueblo Harakbut se refleja, sobre todo, en su régimen económico. Frente al avance de los colonos y de los capitalistas industriales, los Harakbut utilizan mecanismos fácticos y jurídicos para hacerle frente a esta transformación económica inminente. Actualmente existen varias comunidades indígenas Harakbut que trabajan bajo el régimen del capital, inclusive los propios indígenas son los que emplean a los colonos como trabajadores asalariados para la extracción del oro, así como en otras actividades económicas. Pero también existen otras comunidades nativas Harakbut que luchan y apuestan por su régimen económico ancestral, pese a que pareciera que están yendo contra corriente, ellas se alejan de los centros poblados y de las ciudades, para conservar su régimen económico, sin embargo siempre están amenazados, sobre todo por la industria petrolera, de ser desplazados o de que terceros contaminen sus tierras y aguas, frente a ello los Harakbut resisten, es una resistencia del día a día.

El régimen capitalista, cuando incursiona en territorios económicos no capitalistas, revoluciona, desde los cimientos, las fuerzas productivas sociales, que involucra tecnología, instrumentos de trabajo sofisticados, automatización, división social del trabajo compleja, maquinaria moderna, etc., pero además, cambia radicalmente las relaciones sociales de producción, entre los nuevos capitalistas y los nuevos trabajadores asalariados, se protege la propiedad privada capitalista, se hacen necesarias las leyes y la policía para garantizar el nuevo régimen, etc. Todos estos cambios materiales producen cambios en la subjetividad individual y colectiva de las personas involucradas, por ejemplo, las transformaciones en la economía de la comunidad nativa cambian al propio indígena. Cuando incursiona el capitalismo en las comunidades indígenas, cambia la subjetividad indígena, se mira con otros ojos el dinero, el oro, la plata, sabe que a cambio de la venta de su fuerza de trabajo recibirá un salario con el cual podrá adquirir cualquier mercancía que desee y que este en el rango de poder adquisitivo del indígena.

Para hacerle frente a todo este proceso de alienación impuesta por los cambios en el régimen económico, los pueblos indígenas, específicamente los pueblos Harakbut, Yine y Matsigenka, mediante sus organizaciones indígenas representativas, la Federación Nativa del Río Madre de Dios y Afluentes (FENAMAD) y el Consejo Harakbut Yine Matsigenka (COHARYIMA), impulsaron, desde la década de 1980, la creación de la Reserva Comunal Amarakaeri (RCA), siendo reconocido por el Estado Peruano recién en el año 2000, y categorizado como reserva comunal en el año 2002. La Reserva Comunal Amarakaeri es una manera de proteger no solo la naturaleza y el territorio, sino también el régimen económico ancestral de los Harakbut.

Las voces de resistencia a nivel de organizaciones indígenas son la FENAMAD y COHARYIMA. Federación Nativa del Río Madre de Dios y Afluentes 
(FENAMAD) es una organización indígena birregional (Madre de Dios y Cusco) que representa a más de 30 comunidades originarias, agrupadas en siete pueblos indígenas. Desde su creación, en el año 1982, la FENAMAD está comprometida con la defensa del territorio ancestral, de los derechos de los pueblos indígenas, de la cultura, el idioma, de la prerrogativa de participar en los planes y proyectos que los beneficie, etc.

Por otro lado está el Consejo Harakbut, Yine, Matsigenka (COHARYIMA), que es una organización intermedia de la FENAMAD afiliada a la AIDESEP, creada en el año 1993 y consolidada en el año 1998, desde entonces lucha por la defensa de sus territorios y por la protección a las comunidades nativas Harakbut, Yine y Matsigenka, por la cultura, la identidad, el idioma y por la preservación del medio ambiente. Además de estas dos organizaciones están, a nivel nacional, la Asociación Interétnica de Desarrollo de la Selva Peruana (AIDESEP), a nivel internacional, la Coordinadora de las Organizaciones Indígenas de la Cuenca Amazónica (COICA), la Coordinadora Andina de Organizaciones Indígenas (CAOI), etc.

Finalmente, la resistencia y la lucha de los pueblos indígenas, especialmente del pueblo Harakbut, no debe centrarse en una lucha contra las doctrinas y las políticas neoliberales, contra tal o cual élite económica nacional o internacional, contra el Estado monista, la lucha necesaria y fundamental, debería de ser contra el régimen económico-social capitalista. Al luchar contra el régimen del capitalismo estaremos luchando contra la barbarie, el saqueo, la contaminación, la desigualdad económica, la discriminación, la corrupción política, el racismo, la injusticia, la opresión del capital, el dinero y las otras mercancías, la propiedad privada. Probablemente, en el proceso de construcción de un nuevo régimen superior al capitalista, rescatemos algunas lecciones los pueblos indígenas, como el colectivismo en la producción y distribución de los valores de uso, así como el respeto a la naturaleza y una convivencia en equilibrio con el medio ambiente.

\section{Conclusiones}

El régimen económico-social capitalista amenaza con la destrucción del régimen económico-social de la comunidad ancestral de los pueblos Harakbut, Yine y Matsigenka, y como consecuencia de ello, existe la posibilidad real de la desaparición de las relaciones sociales productivas de la comunidad ancestral. De hecho, existen varias comunidades nativas en Madre de Dios que han transformado su régimen económico, ahora los indígenas, en esas comunidades nativas, trabajan, adquieren valores de uso, comercian, producen mercancías, etc., en el marco del régimen capitalista de producción, empieza a ser más importante el dinero, la mercancía, la propiedad privada, el salario, el capital, la jornada de trabajo, la venta de fuerzas de trabajo, etc., que la preservación de la cultura, el territorio, el medio ambiente, la identidad, las costumbres, la cosmovisión originaria, el idioma originario, etc. 
Sin embargo no todo es negativo, existe un movimiento indígena cada vez más fuerte, con organizaciones indígenas representativas consolidadas, con un progresivo reconocimiento por parte de los Estados de los Derechos de los Pueblos Indígenas, con varias comunidades indígenas que resisten a la expansión del régimen capitalista en sus territorios y con indígenas e indigenistas que luchan por el rescate, por la conservación y, aún, por el desarrollo de los pueblos indígenas, de su régimen económico comunitario ancestral, por su identidad cultural, por su reconocimiento como actores sociales activos, por proteger sus territorios, por su participación en los asuntos políticos nacionales y regionales, etc. Para este fin, el desarrollo de los Derechos de los Pueblos Indígenas, de la doctrina y de las leyes, ha sido sumamente importante, pero limitado, pues estas leyes y doctrinas aceptan el régimen capitalista de producción como válido, sabiendo bien que, el origen de las agresiones, vulneraciones y amenazas a los pueblos indígenas, a sus territorios y a la naturaleza, históricamente, está íntimamente vinculado al régimen de producción, circulación y distribución capitalista.

La resistencia, y sobre todo la lucha, de los pueblos indígenas es una constante, del día a día, en las comunidades nativas y en las organizaciones indígenas representativas, esperemos que su lucha como trabajadores asalariados indígenas pronto se sume a los otros sectores sociales que luchan también por una mejor sociedad, racional y científica, a los trabajadores asalariados de las urbes y a los trabajadores asalariados del ande. Muy probablemente esta unión será más eficiente y podremos resolver los problemas medulares de nuestra sociedad, respetando las diferentes culturas y a la naturaleza.

\section{Bibliografía}

GOUVERNEUR, Jacques, “Les Fondements de l'Economie Capitaliste : Introduction à l'Analyse Économique Marxiste du Capitalisme Contemporain", troisième Edition, Louvain la Neuve, Diffusion Universitaire Ciaco, Paris, 2005.

RALPH, Miliband, "The State in Capitalist Society: an analysis of the Western system of power", Basic Books, Inc., Publishers, New York, 1969.

OPAS, Minna,"Different but the Same, Negotiation of personhoods and Christianities in Western Amazonia", academic dissertation, Department of Comparative religion, University of Turku, Finland, 2008.

CHUECAS CABRERA, Adda, "El Derecho de los Pueblos Indígenas y Comunidades en el Contexto Histórico del Perú", Centro Amazónico de Antropología y Aplicación Práctica (CAAAP), Lima. 
GÁLVEZ DURAND, Claudia, Corisepa Dreve, Rómulo y otros, “Reserva Comunal Amarakaeri - Plan Maestro 2008-2012", Edit.: Intendencia de Áreas Naturales Protegidas, Lima, 2008.

GÓMEZ, Magdalena, "Derecho Indígena y Constitucionalidad", http://www. geocities.com/relaju/mgomez.html.

HARGUINDEGUY, Juan Manuel, "Un Largo Camino Hacia el Reconocimiento de Derechos Indígenas", Edit.: Universitat Pompeu Fabra, Barcelona, 2010.

I. ANDRÉIEV, G. KURSÁNOV y otros, "Materialismo Dialéctico", Edit.: Ediciones Estudio, Buenos Aires, 1973.

CLAVERO, Bartolomé, "Los Derechos de los Pueblos Indígenas", Instituto Interamericano de Derechos Humanos, Serie: Estudios Básicos de Derechos Humanos, Tomo VII, Madrid, 1993.

J. PLEJÁNOV, “El Materialismo Histórico”, Ediciones en Lenguas Extranjeras Moscú, Ginebra, 1896.

ORGANIZACIÓN INTERNACIONAL DEL TRABAJO (OIT), "Los Derechos de los Pueblos Indígenas y Tribales en la Práctica: Una guía sobre el Convenio Núm. 169 de la OIT", Departamento de Normas Internacionales del Trabajo, 2009.

LUMBRERAS, Luis Guillermo, Kaulicke, Peter y otros, "Compendio de Historia Económica del Perú", Tomo I: Economía Prehispánica, Editor: Carlos Contreras, segunda edición, Edit.: Banco Central de Reserva del Perú y el Instituto de Estudios Peruanos, Lima, 2010.

NOEJOVICH, Hector, Salazar-Soler, Carmen y otros, "Compendio de Historia Económica del Perú", Tomo II: Economía del Periodo Colonial Temprano, Editor: Carlos Contreras, primera edición, Edit.: Banco Central de Reserva del Perú y el Instituto de Estudios Peruanos, Lima, 2009.

MOORE HUYETT, Thomas Rutherford, "Los Harakbut, su territorio y sus Vecinos", Informe Pericial Antropológico presentado al Tribunal Constitucional del Perú, Lima, 2015.

K. OSTROVITIÁNOV, L. Leóntiev y otros, "Manual de Economía Política”, tercera edición, Edit.: Editorial Cartago, Buenos Aires, 1969.

SUÁREZ RODRÍGUEZ, Flor, Ruiz Calderón, Richard y otros, "Perú: Condiciones de Vida de la Población Según Origen Étnico", Instituto Nacional de Estadística e Informática, Lima, 2016. 
V. S. POKROVSKI, C. S. Vasetski y otros, "Historia de las Ideas Políticas", Traducido por Carlos Marín Sánchez, Edit.: Editorial Grijalbo S. A., México D. F., 1966.

YRIGOYEN FAJARDO, Raquel, “Pluralismo jurídico, Derecho Indígena y Jurisdicción Especial en los Países Andinos", publicado en el Otro Derecho, número 30, Bogotá, 2014.

Constitución Política del Estado Peruano.

Convenio $N^{\circ} 169$ de la Organización Internacional de Trabajo (OIT) sobre pueblos indígenas y tribales en países independientes.

Declaración de las Naciones Unidas sobre los Derechos de los Pueblos Indígenas. Ley $\mathrm{N}^{\circ}$ 29785, Ley del derecho a la consulta previa a los pueblos indígenas u originarios, reconocido en el Convenio 169 de la Organización Internacional del Trabajo (OIT).

Decreto Supremo Nº01-2012-MC, Reglamento de la Ley N²9785. 